\title{
Edukasi Periode Emas 1000 Hari Pertama Kehidupan
}

\author{
Julaecha \\ Program Studi D-III Kebidanan STIKes Baiturrahim Jambi \\ email:echa_mamee@yahoo.com
}

Submitted : 03/04/2020

Accepted: 03/08/2020

Published: 24/11/2010

\begin{abstract}
The first 1000 days of life (HPK) movement is a movement to accelerate nutritional improvement. In this period the child's brain develops rapidly, although the human brain will continue to develop and can experience changes throughout life, but at this time the fastest development. The Indonesian government has committed and worked hard to accelerate the improvement of nutrition for the lives of children of the nation's next generation. The government's commitment has been stated through government regulation No. 42 of 2013 concerning the national movement to improve nutrition. Community service aims to increase the knowledge and understanding of pregnant women and mothers of children under the age of 1,000 HPK nutrition as a critical period that must be considered. Counseling method using the first 1000 days of the booklet of life published by the Ministry of Health of the Republic of Indonesia. Community service is followed by pregnant women and mothers who have toddlers in the class of pregnant women and toddlers, held in November-December 2019 at BPM Rosmala Aini. The result of this community service is an increase in maternal understanding of the importance of nutrition from pregnancy to 2-year-old children, and it is hoped that the coverage of mothers giving breastfeeding in the first hour and exclusive breastfeeding increases.
\end{abstract}

Keyword:1000 HPK, mother of children under five, nutrition, pregnant women

\begin{abstract}
Abstrak
Gerakan 1000 hari pertama kehidupan (HPK) merupakan suatu gerakan percepatan perbaikan gizi. Pada periode ini otak anak berkembang dengan pesat, meskipun otak manusia akan terus berkembang dan dapat mengalami perubahan sepanjang hidup, namun pada masa ini perkembangannya paling cepat. Pemerintah Indonesia telah berkomitmen dan bekerja keras mempercepat perbaikan gizi untuk kehidupan anak-anak generasi penerus bangsa. Komitmen pemerintah telah di nyatakan melalui peraturan pemerintah No. 42 Tahun 2013 tentang gerakan nasional perbaikan gizi. Pengabdian kepada masyarakat ini bertujuan untuk meningkatkan pengetahuan dan pemahaman ibu hamil dan ibu yang mempunyai balita tentang nutrisi 1000 HPK sebagai masa kritis yang harus diperhatikan. Metode penyuluhan dengan menggunakan booklet 1000 hari pertama kehidupan yang di terbitkan oleh kemenkes RI, Pengabdian kepada masyarakat ini diikuti oleh ibu hamil dan ibu yang mempunyai balita pada kelas ibu hamil dan kelas ibu balita, dilaksanakan pada bulan November- Desember 2019 di BPM Rosmala Aini. Hasil dari pengabdian kepada masyarakat ini adalah peningkatan pemahaman ibu tentang pentingnya nutrisi mulai dari kehamilan sampai anak berusia 2 tahun, dan diharapakna cakupan ibu yang memberikan ASI pada 1 jam pertama dan ASI Esklusif meningkat.
\end{abstract}

Kata Kunci: 1000 HPK, ibu balita, ibu hamil, nutrisi 


\section{PENDAHULUAN}

Masalah gizi di Indonesia masih menjadi masalah yang serus dan memebutuhkan perhatian karena akan berdampak terhadap kualitas sumber daya manusia. Perbaikan gizi dengan cara peningkatan mutu gizi individu dan komunitas tertuang dalam undang-undang no.36 tahun 2009 dan Peraturan presiden no.42 tahun 2013 tentang percepatan perbaikan gizi pada 1000 hari pertama kehidupan (HPK). (Kementerian Kesehatan RI, 2016)

Gizi merupakan dasar dan pondasi dalam berbagai aspek yang memberi kontribusi pembangunan suatu bangsa berhubungan dengan kualitas sumber daya manusia (SDM) pada 1000 hari pertama kehidupan (HPK) merupakan suatu periode didalam proses pertumbuhan dan perkembangan yang dimulai sejak konsepsi sampai anak berusia 2 tahun. Asupan makanan selama 1000 HPK memberi konsekuensi kesehatan untuk masa depan agar anak tumbuh sehat cerdas maka gizi sejak anak dini harus terpenuhi dengan tepat dan optimal. (Achadi, EL 2014)

Faktor gizi ibu sebelum dan selama kehamilan merupakan penyebab tidak langsung yang memberikan kontribusi terhadap pertumbuhan dan perkembangan janin, ibu hamil dengan gizi kurang akan menyebabkan janin mengalami Intra Uterine Growth Retardatation (IUGR), sehingga bayi akan lahir dengan kurang gizi, dan mengalami gangguan pertumbuhan dan perkembangan serta rentan terhadap penyakit degeneratif saat dewasa kelak. (Victoria, 2008)

Pengetahuan, sikap dan praktik 1000 HPK menjadi hal penting terutama ibu untuk masa pertumbuhan dan perkembangan baduta yang terhitung mulai dari 0 hari kehamilan samapai balita berusia 2 tahu, Pengetahuan ini akan bertambah baik dengan sikap dan praktik ibu terkait gizi seimbang. Pengetahuan di dapat dari berbagai sumber anatara lain: posyandu, televisi dan buku. (Abuya et al 2012)

Berdasarkan data dari dinas kesehatan Kota Jambi tahun 2019 cakupan ibu yang memberikan ASI Esklusif masih di bawah target nasional yaitu $63,69 \%$ yang seharusnya 80-100\% semua ibu memberikan ASI Ekslusif. Bidan Praktik Manadiri (BPM) Rosmala Aini merupakan bidan praktik swasta yang memberikan pelayanan kehamilan, persalinan, nifas, bayi baru lahir dan pelayanan
Kontrasepsi. Berada di wilayah kerja Puskesmas Paal Merah I Kota Jambi.

Perilaku gizi sangat penting karena hal ini merupakan penyebab langsung dari masalah gizi di Indonesia. Gizi pada 1000 hari pertama kehidupan ini penting karena jika tidak di pantau dengan baik akan berdampak pada pertumbuhan dan perkembangan anak nantinya. dengan harapan gizi yang optimal selama 1000 HPK membuat kemampuan anak untuk tumbuh dan berkembang serta belajar lebih baik.

\section{TARGET DAN LUARAN}

\section{Target}

1) Peningkatan pengetahuan ibu hamil dan Ibu yang mempunyai balita tentang pentingnya nutrisi pada 1000 HPK melalui pemberian penyuluhan

2) Cakupan pemberian ASI Ekslusif meningkat

\section{Luaran}

Luaran dari pengabdian kepada masyarakat tentang nutrisi pada 1000 hari pertama kehidupa adalah pemahaman ibu tentang pentingnya nutrisi pada 1000 hari pertama kehidupan dan menimgkatnya cakupan pemberian ASI Ekslusif

\section{METODE PELAKSANAAN}

1. Mengurus surat Izin pengabdian masyarakat

2. Mengidentifikasi pengetahuan ibu tentang nutrisi 1000 hari pertama kehidupan

3. Memberikan penyuluhan tentang

a. Pengertian tentang 1000 hari pertama kehdipan

b. Fase-fase dalam 1000 hari kehidupan

c. Efek jangka pendek dan jangka panjang dalam HPK

d. Penyuluhan tentang ASI Ekslusif

4. Metode diskusi tanya jawab

5. Penutup

Pelaksanaan Pengabdian Kepada

Masyarakat ini dilakukan di BPM Rosmala

Aini, SST. Pada bulan November sampai

Desember 2019

Media yang digunakan pada pengabdian ini adalah LCD, Laptop, power point,Leaflet.

\section{HASIL DAN PEMBAHASAAN}

Hasil dari kegiatan pengabdian kepada masyarakat ini adalah penyuluhan tentang 
nutrisi 1000 hari pertama kehidupan pada ibu hamil dan ibu yang mempunyai balita yang mengikuti kelas ibu dan balita di BPM Rosmala Aini. Dengan adanya kelas ibu balita dan kelas ibu hamil yang rutin dilaksanakan, sebanyak $2 \mathrm{x}$ pertemuan. Ibu Hamil, ibu menyusui, bayi baru lahir dan anak usia 2 tahun (Baduta) merupakan kelompok sasaran untuk meningkatkan kualitas kehidupan 1000 hari pertama kehidupan.

1000 HPK adalah periode seribu hari sejak terjadi konsepsi hingga anak berumur 2 tahun. Dimana 270 hari selama kehamilan, dan 730 hari kehidupan pertama sejak bayi dilahirkan. Periode ini disebut periode emas (golden periode) atau disebut juga sebagai waktu kritis, yang jika tidak dimanfaatkan dengan baik akan terjadi keruskaan yang bersifat permanen. (Kementrian Koordintor Bidang Kesejahteraan Rakyat 2013)

Pada 1000 hari pertama kehidupan (HPK) otak anak berkembang dengan pesat, meskipun otak manusia akan terus berkembang dan dapat mengalami perubahan sepanjang hidup, inilah masa perkembangan paling cepat. Apa yang terjadi pada diri anak pada masa sensitif ini akan menjadi fondasi bagi pertumbuhan dan perkembangan anak pada tahapan selanjutnya, bahkan berdampak hingga masa dewasa. Keluarga sebagai lingkup pertama dan utama bagi anak memiliki peranan yang sangat besar dalam perencanaan dan penurunan angka stunting, tidak bisa hanya bergantung pada praktisi dan tenaga profesional di bidang kesehatan. Oleh karena itu, pendidikan keluarga tentang pemenuhan gizi dan pemberian stimulasi yang baik pada 1000 hari pertama kehiduan anak menjadi kunci. (Kementrian pendiidkan dan kebudayaan 2019)

Gizi merupakan dasar dan pondasi dalam berbagai aspek yang memberi kontribusi pembangunan suatu bangsa yang berhubungan dengan kualitas sumber daya manusia (SDM) 1000 hari pertama kehidupan atau first thousand days merupakan suatu periode didalam proses pertumbuhan dan perkembangan yang di mulai sejak konsepsi sampai anak berusia 2 tahun. Asupan makanan selama 1000 hari pertamaa kehidupan memberi konsekuensi kesehatan untuk masa depan agar anak tumbuh sehat dan cerdas maka gizi sejak anak dini harus terpenuhi dengan tepat dan optimal. (Achadi, EL, 2014)
Kecukupan gizi yang optimal selama 1000 HPK membuat kemampuan anak tumbuh dan berkembang serta belajar lebih baik. Hasil pemeriksaan IQ anak usia 22 bulan dapat menjadi indikator kemampuan akademik di usia dewasa. (Kementrian Kesehatan RI, 2016)

Penelitian Riset kesehatan dasar (Riskesdas 2018) 7 (tujuh) juta anak-anak Indonesia mengalami gagal tumbuh atau stunting. Dimana penyebabnya tidak hanya di picu oleh masalah kemiskinan, akan tetapi sebagian ada juga dari keluarga mampu namun terkena stunting disebabkan karena gaya hidup yang tidak sehat. (Riskesdas 2018)

Dampak buruk yang dapat ditimbulkan oleh masalah gizi antara lain: terganggunya perkembangan otak, kecerdasan, gangguan pertumbuhan fisik, dan gangguan metabolisme tubuh. Sedangkan dampak jangka panjang yaitu: menurunnya kemampuan kognitif, prestasi belajar, kekebalan tubuh mudah sakit (Kementrian pendiidkan dan kebudayaan 2019)

Pesatnya pertumbuhan dan perkembangan selama kehamilan, menyusui dan anak usia di bawah 2 tahun diperlukan kebutuhan gizi tertentu selama setipa tahap sehingga diperlukan kesadaran pentingnya gizi. Oleh karena itu, sangat penting untuk memastikan setiap ibu dan anak medapatkan akses dan pengetahuan gizi yang optimal selama 1000 HPK. ( Kementrian Bidang Kesejahteraan Rakyat, 2013)

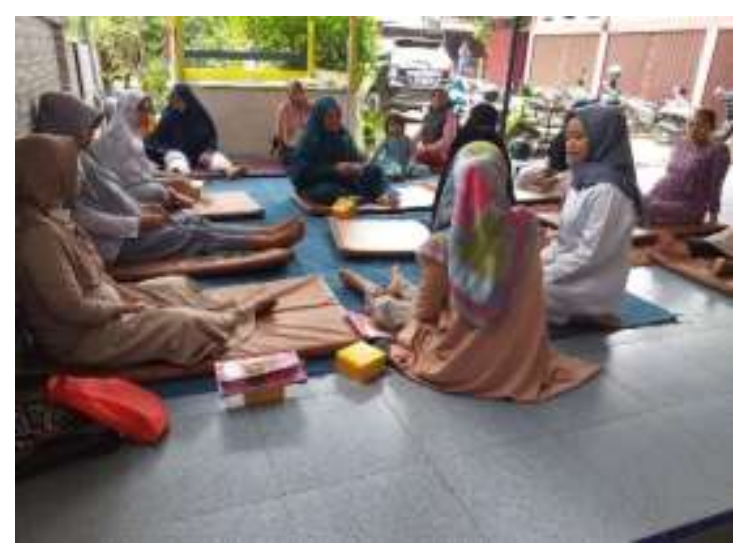



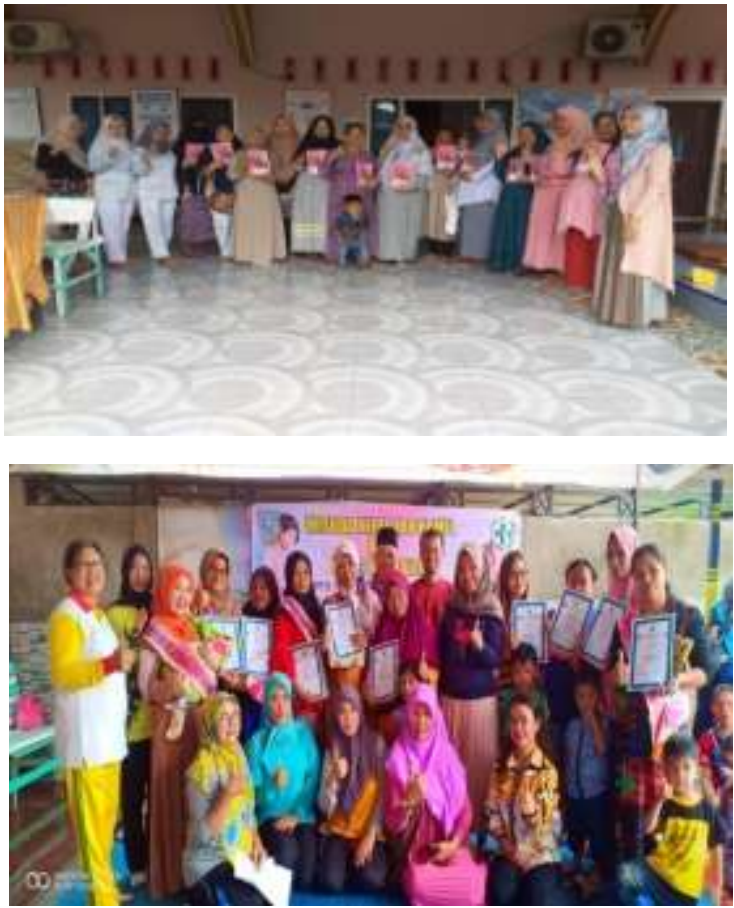

Gambar 1,2,3 Kegiatan Penyuluhan

\section{KESIMPULAN DAN SARAN}

\section{Kesimpulan}

Penyuluhan yang dilakukan pada kelas ibu hamil dan kelas ibu balita tentang Nutrisi pada 1000 hari pertama kehidupan terhadap 23 peserta kelas ibu hamil dan kelas ibu balita dilakukan di BPM Rosmala Aini, sebanyak 2x pertemuan, yang bertujuan agar nutrisi pada ibu hamil adekuat dan peningkatan pengetahuan ibu balita tentang pentingnya nutrisi pada 1000 hari pertama kehidupan sehingga tidak terjadi stunting serta peningkatan cakupan pemberian ASI satu jam pertama kelahiran, dan ASI Ekslusif sampai usia 6 Bulan .

\section{Saran}

Intervensi spesifik secara kontinue dengan memberikan penyuluhan, pembagian leaflet atau pemasangan famplet sebagai upaya yang sangat penting untuk menyelamatkan 1000 hari pertama kehidupan dan perlunya intervensi gizi pra konsepsi yang dapat diberikan pada saat pra nikah.

\section{UCAPAN TERIMA KASIH}

Terima kasih kepada Bapak Ketua Sekolah Tinggi Ilmu Kesehatan Baiturrahim Jambi yag telah memberikan dana dan Ibu Rosmala Aini, SST selaku pimpinan PMB Rosmala Aini yang telah memberikan izin memfasilitasi kegiatan pengabdian masyarakat ini

\section{DAFTAR PUSTAKA}

Abuya et al.2012. Effect of Mother's education on child's nutrition status in the slum of Nairobi. Biomed Central 12:80

Achadi, EL 2014 Periode Kritism 1000 HPK dan Dampak Jangka Panjang Terhadap kesehatan dan Fisiknya, FKM Universitas Indnesia

Atien Nur Hamida. Pentingnya Stimulasi Dini Bagi Tumbuh embang Otak Anak. Maeri talk show Tumbuh kembang dan kesehatan Anak di UNY 17 Oktober 2009

Kementerian Kesehatan RI, 2016 Biro Komunikasi dan Pelayanan Masyarakat 1000 HPK.

Kementerian Kesehatan RI, 2015 Pusat Komunikasi Publik

Kusumawati,dkk, 2013 Model Pengendalian Faktor Kejadian Stunting pada Anak Usia 6-36 Bulan di Puskesmas Kedung Banteng, Laporan Penelitian. LPPM UNSOED

Kementrian Koordintor Bidang Kesejahteraan Rakyat 2013, Kerangka Kebijakan Gerakan Nasional Percepatan Perbaikan Gizi dalam Rangka Seribu Hari Pertama Kehidupan (Gerakan 1000 HPK)

Kemendikbud, 2019. Modul pendidikan keluarga pada 1000 hari perama kehiduan, direktorat pembinaan pendidikan keluarga. Direktorat jendral pendiidkan anak usia dini dan pendidikan masyarakat. Kementrian pendidikan dan kebudayaan 2019.

Riskesdas 2018, Badan Penelitian dan Pengembangan Kesehatan. Kementrian kesehatan.https://labdata.litbang.depkes.go .id/menu-progress-puldata/progresspuldata-rkd-2018 